\title{
The clinical meaning of obsessive-compulsive symptoms in bipolar disorder and schizophrenia.
}

Article in Australian and New Zealand Journal of Psychiatry · February 2015

CITATIONS

4

9 authors, including:

\section{Matteo Tonna}

University Hospital of Parma

49 PUBLICATIONS 184 CITATIONS

SEE PROFILE

Francesca Paglia

Università degli studi di Parma

11 PUBLICATIONS 24 CITATIONS

SEE PROFILE
READS

52

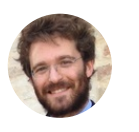

Andrea Amerio

Università degli studi di Parma

26 PUBLICATIONS 144 CITATIONS

SEE PROFILE

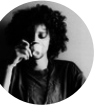

Paolo Ossola

Università degli studi di Parma

37 PUBLICATIONS 123 CITATIONS

SEE PROFILE

Some of the authors of this publication are also working on these related projects: 


\section{Letter}

\section{The clinical meaning of obsessive-compulsive symptoms in bipolar disorder and schizophrenia \\ Matteo Tonna', Andrea Amerio 2,3, Rebecca Ottoni², Francesca Paglia ${ }^{2}$, Anna Odone 4,5 , Paolo Ossola ${ }^{2}$, Chiara De Panfilis ${ }^{2}$, $S$ Nassir Ghaemi3,6 and Carlo Marchesi $^{2}$}

'Department of Mental Health, Local Health Service, Parma, Italy

2Department of Neuroscience, Section of Psychiatry, University of Parma, Parma, Italy 3 Mood Disorders Program, Tufts Medical

Center, Boston, MA, USA

${ }^{4}$ School of Medicine-Public Health Unit, University of Parma, Parma, Italy

${ }^{5}$ Department of Global Health and Social Medicine, Harvard Medical School, Boston, MA, USA

${ }^{6}$ Tufts University Medical School, Department of Psychiatry and Pharmacology, Boston, MA, USA

Corresponding author:

A Amerio, Section of Psychiatry, Department of Neuroscience, University of Parma, c/o Ospedale Maggiore, Pad. 21 - Braga, Viale A. Gramsci 14, 43I26 Parma, Italy.

Email: andrea.amerio@studenti.unipr.it

DOI: | 0.1 | 77/ $00048674 \mid 5572010$

To the Editor

The rate of co-morbid obsessivecompulsive disorder (OCD) with both bipolar and schizophrenia spectrum disorders is high. The lifetime prevalence of bipolar disorder (BD) in OCD patients is up to $21.5 \%$ and almost $50 \%$ of OCD patients have cyclothimic traits (D'Ambriosio et al., 2010). Co-morbid OCD is diagnosed in $8-32 \%$ of patients with schizophrenia (SCZ) and in up to $35 \%$ of patients

Australian \& New Zealand Journal of Psychiatry I-I

(C) The Royal Australian and New Zealand College of Psychiatrists 2015 Reprints and permissions: sagepub.co.uk/journalsPermissions.nav anp.sagepub.com

(S)AGE

with schizotypal personality disorder (de Haan et al., 20I3).

On one hand, BD-OCD is associated with poorer functioning as compared to 'pure' BD or 'pure' OCD (Amerio et al., 2014). On the other hand the impact of OC symptoms (OCS) on functioning in SCZ might depend on their severity: OCS might have an improving effect while a fullblown OCD might have a worsening one (de Haan et al., 20I3). In line with these findings, preliminary results of our recent study have showed a gradual transition from an improving effect (mild OCS) to a worsening one (moderate-severe OCS) on functioning in SCZ subjects.

OC symptoms are mediated by fronto-striato-thalamic circuits which have a crucial role in the regulation of daily master routines and sub-routines. Since these circuits can also be involved in the pathogenesis of BD and SCZ, OCS may have different clinical meanings in these disorders:

I. they may be an expression of a vulnerability to the development of BD and SCZ. This hypothesis implies that OCS may be the prodromic manifestations of both disorders, preceding their clinical onset for many years (D'Ambrosio et al., 20I0). This means that OCS in adolescence or early adulthood can predispose to either BD or SCZ;

2. they may have a pathoplastic influence, especially in 'soft' bipolar and schizophrenia spectrum disorders (cyclothimia and schizotypal personality disorder); in other words OCS may constitute the superficial symptoms 'shell', covering the inner affective or psychotic core thorough the course of illness (and perhaps preventing the development of a full-blown disorder);
3. they might confer, at a mild level of severity, order and stability to daily life activity, thus compensating functioning decline in SCZ and possibly exerting a similar effect in $\mathrm{BD}$;

4. by contrast, they may have a different relationship with $\mathrm{BD}$ or SCZ symptoms, since OCS appear to be independent from negative or positive symptoms in SCZ, while in BD they appear more often - and sometimes exclusively - during depressive episodes (the most frequent phase of disorder), remitting during manic/hypomanic episodes (Amerio et al., 20l4).

\section{Funding}

This research received no specific grant from any funding agency in the public, commercial or not-for-profit sectors.

\section{Declaration of interest}

Dr Ghaemi has provided research consulting to Sunovion and Pfizer, and has obtained a research grant from Takeda Pharmaceuticals. Neither he nor his family hold equity positions in pharmaceutical corporations. The other authors report no conflicts of interest.

\section{References}

Amerio A, Odone A, Marchesi C, et al. (2014) Do antidepressant-induced manic episodes in obsessive-compulsive disorder patients represent the clinical expression of an underlying bipolarity? Australian and New Zealand Journal of Psychiatry 48: 957-963.

de Haan L, Sterk B, Wouters L, et al. (2013) The 5-year course of obsessive-compulsive symptoms and obsessive-compulsive disorder in first-episode schizophrenia and related disorders. Schizophrenia Bullettin 39: 15I-160.

D'Ambrosio V, Albert U, Bogetto F, et al. (2010) Obsessive-compulsive disorder and cyclothymic temperament: an exploration of clinical features. Journal of Affective Disorders 127: 295-299. 